\title{
MDM2 SNP309 modifies the prognostic significance of the p53 mutational status in patients with ovarian cancer
}

\author{
GERDA HOFSTETTER $^{1}$, ASTRID BERGER ${ }^{1}$, EVA-MARIA BAUER ${ }^{1}$, EVA SCHUSTER $^{2}$, ANDREA WOLF $^{2}$, \\ MARTINA CHAMSON ${ }^{1}$, ELISABETH MÜLLER-HOLZNER ${ }^{1}$, DANIEL REIMER ${ }^{1}$, ELENA I. BRAICU ${ }^{3}$, \\ JALID SEHOULI $^{3}$, HANNO ULMER $^{4}$, DAN CACSIRE CASTILLO-TONG ${ }^{2}$, \\ ROBERT ZEILLINGER ${ }^{2}$ and NICOLE CONCIN ${ }^{1}$
}

\begin{abstract}
${ }^{1}$ Department of Gynecology and Obstetrics, Medical University Innsbruck, A-6020 Innsbruck; ${ }^{2}$ Department of Obstetrics and Gynecology, Molecular Oncology Group, Medical University of Vienna, A-1090 Vienna, Austria; ${ }^{3}$ Department of Gynecology, European Competence Center for Ovarian Cancer, Campus Virchow Klinikum, Charité - Universitätsmedizin Berlin, Augustenburger Platz 1, D-13353 Berlin, Germany; ${ }^{4}$ Department of Medical Statistics, Informatics, and Health Economics, Medical University Innsbruck, Anichstrasse 35, A-6020 Innsbruck, Austria
\end{abstract}

Received July 14, 2011; Accepted August 30, 2011

DOI: $10.3892 /$ or.2011.1560

\begin{abstract}
A single nucleotide polymorphism (SNP309) of MDM2 causes elevated MDM2 levels and an attenuation of p53 function. The aim of the present study was to examine the clinical relevance of the MDM2 SNP309 in ovarian cancer. MDM2 SNP309 genotype was analyzed in 198 patients with primary ovarian cancer. MDM2 expression was investigated using immunohistochemistry. A functional yeast-based assay and subsequent sequencing were performed to determine p53 mutational status. Of the patients, $44.4 \%$ (88 of 198) exhibited the common variant (T/T), $40.9 \%$ (81 of 198) the heterozygous variant (T/G) and $14.7 \%$ (29 of 198) the homozygous variant (G/G) MDM2 SNP309 genotype. MDM2 SNP309 was not associated with p53 mutational status, MDM2 expression, clinicopathological parameters or prognosis. In patients with the $\mathrm{T}$ allele (T/T and T/G genotype), p53 wild type carcinomas were associated with significantly improved recurrence-free $(\mathrm{p}<0.001)$ and overall survival $(\mathrm{p}<0.001)$ as compared to $\mathrm{p} 53$ mutant carcinomas. In contrast, p53 mutational status did not possess prognostic relevance in $\mathrm{G} / \mathrm{G}$ carriers. A possible functional impairment of the p53 pathway caused by the $\mathrm{G} / \mathrm{G}$ genotype of the MDM2 SNP309 may modify the association between 553 mutational status and prognosis in ovarian cancer.
\end{abstract}

\section{Introduction}

MDM2 (mouse double minute 2 homolog) is a crucial negative regulator of the tumor suppressor p53. MDM2 directly binds

Correspondence to: Dr Nicole Concin, Department of Gynecology and Obstetrics, Medical University Innsbruck, Anichstrasse 35, A-6020 Innsbruck, Austria

E-mail: nicole.concin@i-med.ac.at

Key words: MDM2 SNP309, mouse double minute 2 homolog, p53, ovarian cancer to the $\mathrm{N}$-terminus of $\mathrm{p} 53$, thereby inhibiting its transcriptional activation function. In addition, MDM2 possesses E3 ubiquitin ligase activity that targets p53 for modification and subsequent degradation through the $26 \mathrm{~S}$ proteasome (1).

A single nucleotide polymorphism (SNP309, $\mathrm{T} \rightarrow \mathrm{G}$; rs2279744) located in the MDM2 intronic promoter enhances the DNA-binding affinity of the transcriptional activator Sp1. This results in elevated MDM2 levels and consequently, an attenuation of the p53 pathway (2). The initial observation in Li-Fraumeni patients that the G-allele was associated with more malignancies than was the common genotype, suggested that the MDM2 SNP309 impacts cancer susceptibility. This hypothesis was recently supported by a study in mice without germ-line p53 mutations, demonstrating that the G/G genotype correlated with an increased cancer risk and altered tumor spectrum as compared to the common genotype (3). However, case-control studies that aimed to link the MDM2 SNP309 to the formation of sporadic solid tumors have reported inconsistent results. In meta-analyses, the $\mathrm{G} / \mathrm{G}$ genotype was associated with an increased risk for lung, endometrial, and hepatocellular carcinomas, but not for breast or colorectal carcinomas (4-6).

In addition, the $\mathrm{G}$-allele correlated with younger age at tumor diagnosis in patients with Li-Fraumeni syndrome and sporadic soft tissue sarcomas (2). Subsequent studies confirmed accelerated formation of distinct types of sporadic solid tumors, such as oral (7), head and neck (8), pancreas (9), hepatitis-B associated hepatocellular (10), and bladder carcinomas (11). BRCA1/2 associated breast cancer was diagnosed at an earlier age in Jewish-Ashkenazi but not in Caucasian women (12-14). Interestingly, the prevalence of the G/G genotype significantly varies with respect to ethnicity and was $24 \%$ in healthy Jewish-Ashkenazi as opposed to $12 \%$ in Caucasian women (2).

The prognostic value of the MDM2 SNP309 has been evaluated in distinct types of solid tumors. It has constituted an independent prognostic factor in breast (15), lung (16), oral 
squamous (17), gastric (18), and renal carcinomas (19). The aim of the present study was to examine the clinical relevance of the MDM2 SNP309 in patients with ovarian cancer.

\section{Materials and methods}

Patients and tissue samples. Between 1990 and 2004, 198 patients diagnosed with primary ovarian cancer at the Departments of Gynecology and Obstetrics in Innsbruck $(n=137)$, Vienna $(n=31)$, and Berlin $(n=30)$ were enrolled. Clinicopathological features and follow-up data were obtained by retrospective chart review (Table I). This study was approved by the Ethics Committee (project No. UN3507).

DNA extraction. For MDM2 SNP309 analysis, DNA was isolated from paraffin-embedded normal tissue using the QIAamp DNA FFPE Tissue kit (Qiagen, Hilden, Germany) according to the manufacturer's instructions. DNA concentration was measured by spectrophotometer at $260 \mathrm{~nm}$, and DNA purity was determined by the A260/A280 ratio.

Genotyping by pyrosequencing. The SNP309 (rs2279744) was determined by pyrosequencing. The primer pair MDM2_309-SE (5'-GGG GGT GGT TCG GAG GTC T-3') and MDM2_309AS (5'-AGT GAC CCG ACA GGC ACC T-3') was used to amplify a 115 bp fragment of the MDM2 gene (HSU49725). The antisense primer was biotinylated. PCR was performed in a total volume of $25 \mu 1$ including $25 \mathrm{ng}$ total DNA, 5 pmol of sense and antisense primers and $12.5 \mu 1$ JumpStart REDTaq ReadyMix Reaction mix (Sigma, St. Louis, MO, USA), which contains $20 \mathrm{mM}$ Tris-HCl, $\mathrm{pH} 8.3$, $100 \mathrm{mM} \mathrm{KCl}, 4 \mathrm{mM} \mathrm{MgCl} 2,0.002 \%$ gelatin, $0.4 \mathrm{mM}$ each dNTP, inert dye, stabilizers, $0.06 \mathrm{U} / \mu 1 \mathrm{Taq}$ DNA polymerase and JumpStart Taq antibody. The reaction was performed on a Perkin-Elmer GeneAmp PCR system 9600 with 38 cycles at $94^{\circ} \mathrm{C}$ for $30 \mathrm{sec}$, at $58^{\circ} \mathrm{C}$ for $30 \mathrm{sec}$ and $72^{\circ} \mathrm{C}$ for $30 \mathrm{sec}$. The reaction was preceded by a primary denaturation step at $94^{\circ} \mathrm{C}$ for $5 \mathrm{~min}$ and incubation at $72^{\circ} \mathrm{C}$ for $7 \mathrm{~min}$.

Polymorphisms were detected using the Pyrosequencer PSQ 96 and PSQ 96 SNP Reagent kit; $25 \mu 1$ PCR product was used for pyrosequencing according to the manufacturer's instructions, and 5 pmol of the sequencing primer (5'-GGG CTG CGG GGC CGC T-3') were applied to detect the polymorphisms.

Immunohistochemistry. Immunohistochemistry was performed using the UltraView Universal DAB Detection kit (Ventana, Tucson, AZ, USA) on a Ventana BenchMark automated slidestaining system. Antigen-retrieval was performed with the Cell Conditioning Solution 1 (Ventana), pH 8.6 (90 min). The primary MDM2 antibody (Santa Cruz Biotechnology, Santa Cruz, CA, USA) was incubated for $2 \mathrm{~h}$ at $37^{\circ} \mathrm{C}$. Counterstaining was performed with Nexes hematoxylin, followed by Nexes Bluing Reagent (Ventana). Negative controls were obtained by omitting the primary antibody. All slides were evaluated in a blind manner. Cells were classified as positive for MDM2 when the cytoplasm or nucleus or both were stained in more than $10 \%$ of tumor cells. For further statistical analyses, MDM2 expression scores were divided into two groups, positive and negative.
Table I. Clinicopathological parameters in the examined 198 patients with primary ovarian cancer.

\begin{tabular}{lc}
\hline Characteristics & $\mathrm{n}$ \\
\hline Age at diagnosis, median (range) & 61 years (24-88) \\
FIGO stage & 37 \\
I & 11 \\
II & 122 \\
III & 28 \\
IV & \\
Histological subtype & 98 \\
Serous & 34 \\
Endometrioid & 50 \\
Mucinous & 16 \\
Other & \\
Grading & \\
I & 8 \\
II & 99 \\
III & 89 \\
Residual disease & \\
No residual disease & 80 \\
Residual disease $\leq 2 \mathrm{~cm}$ & 52 \\
Residual disease $>2 \mathrm{~cm}$ & 47 \\
\hline
\end{tabular}

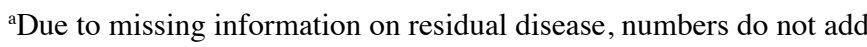
up to 198 patients

p53 mutational analysis. To detect inactivating mutations in the p53 gene, a functional yeast-based assay and subsequent sequencing were performed as previously described (20).

Statistical analysis. The $\chi^{2}$ test was used for pairwise examination of the relationships between MDM2 SNP309, p53 mutational status, and clinicopathological parameters.

Survival probabilities were calculated with the product limit method of Kaplan and Meier, together with the log-rank test. The Cox proportional hazards model was used for multivariate analysis to assess the independent effect of different prognostic factors. The Statistical Package for the Social Sciences for Windows 18.0 software (SPSS, Inc., Chicago, IL, USA) was used for all analyses. Differences were considered statistically significant when $\mathrm{p}<0.05$.

\section{Results}

Of the patients, $44.4 \%$ ( 88 of 198) exhibited the common (T/T), $40.9 \%$ (81 of 198 ) the heterozygous variant $(\mathrm{T} / \mathrm{G})$, and $14.7 \%$ (29 of 198) the homozygous variant (G/G) MDM2 SNP309 genotype. Genotype frequencies were consistent with those predicted by the Hardy-Weinberg equilibrium. Of the primary ovarian cancer specimens, 68.7\% (136 of 198) harbored mutant p53 and 31.3\% (62 of 198) wild-type p53.

The MDM2 SNP309 was not associated with the p53 mutational status or clinicopathological parameters (age, FIGO stage, grading, histological subtype or residual tumor after primary surgery). 

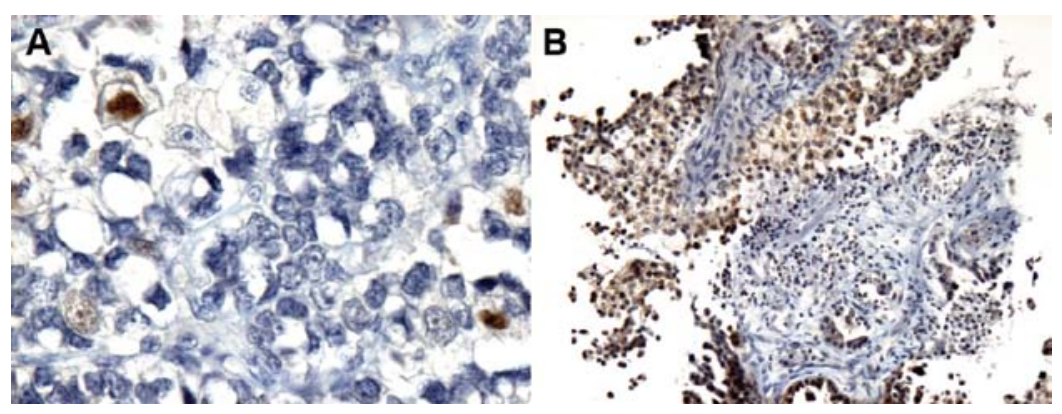

Figure 1. MDM2 protein expression in ovarian cancer specimens. (A) Representative immunostaining confined to the nucleus and (B) localized in the nucleus and the cytoplasm of tumor cells.

A

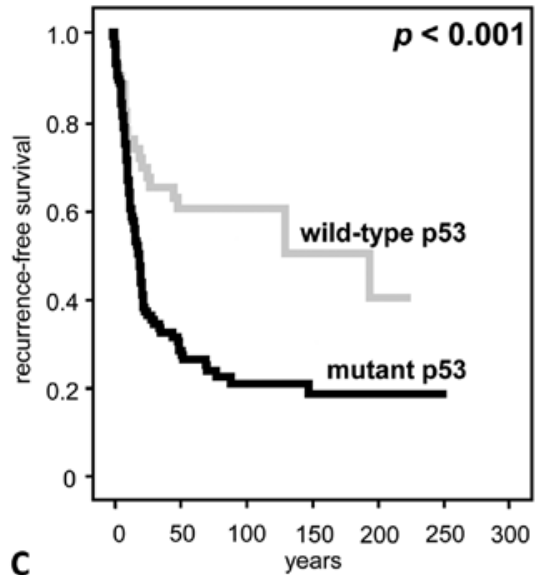

C

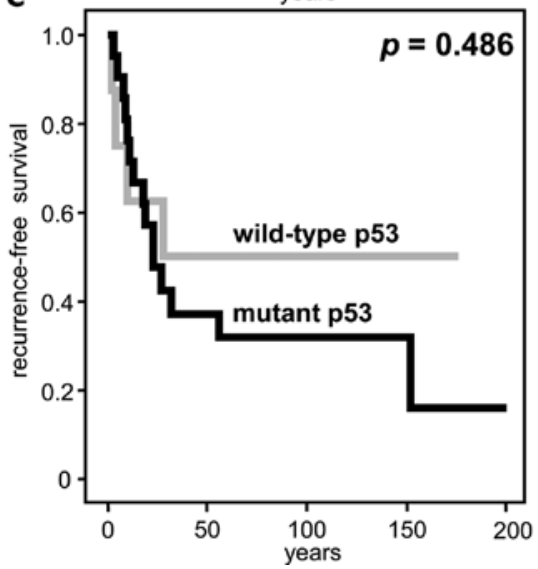

B
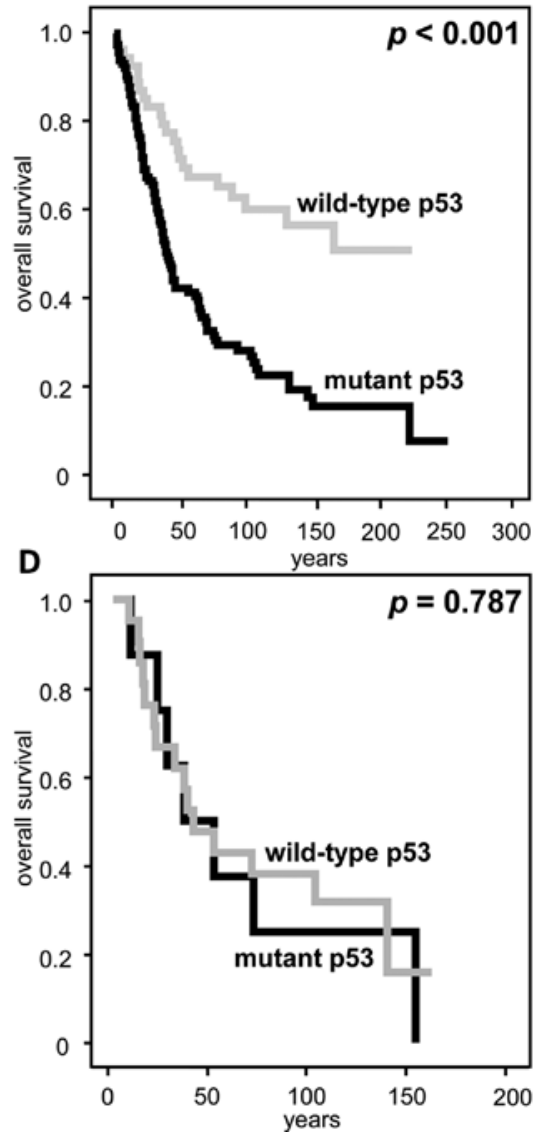

Figure 2. In patients with the T-allele (T/T and T/G genotype), p53 wild-type carcinomas were associated with significantly improved recurrence-free (A) and overall survival (B) as compared to p53 mutant carcinomas. In contrast, the p53 mutational status did not possess prognostic relevance in $\mathrm{G} / \mathrm{G}$ carriers $(\mathrm{C}, \mathrm{D})$.

To investigate the effect of the MDM2 SNP309 on MDM2 protein expression, immunohistochemistry for MDM2 was performed in available cancer specimens $(n=165$, Fig. 1). Positive staining for MDM2 was detected in $16.2 \%$ (12 of 74) of $\mathrm{T} / \mathrm{T}, 21.5 \%$ (14 of 65 ) of $\mathrm{T} / \mathrm{G}$, and $26.9 \%$ (7 of 26 ) of $\mathrm{G} / \mathrm{G}$ MDM2 SNP309 genotype carriers $(\mathrm{p}=0.464)$.

In the entire group of ovarian cancer patients, p53 mutational status constituted a significant prognostic marker. Patients with p53 wild-type carcinomas showed a significantly improved recurrence-free (127.5 vs. 68.7 months, $\mathrm{p}<0.001)$ and overall survival (135.2 vs. 80.4 months, $\mathrm{p}<0.001)$ in comparison to patients with p53 mutant carcinomas.

In patients with the $\mathrm{T}$-allele (T/T and $\mathrm{T} / \mathrm{G}$ genotype), $\mathrm{p} 53$ wild-type carcinomas were associated with significantly improved recurrence-free and overall survival as compared to p53 mutant carcinomas (p53 wild-type vs. p53 mutant; recurrence-free survival 144.7 vs. 76.7 months, $\mathrm{p}<0.001$; overall survival 129.3 vs. 66.4 months, p<0.001) (Fig. 2). In contrast, p53 mutational status did not possess prognostic relevance in G/G carriers (p53 wild-type vs. p53 mutant; recurrence-free survival 93.5 vs. 68.7 months, $\mathrm{p}=0.486$; overall survival 81.9 vs. 90.1 months, $\mathrm{p}=0.787$ ) (Fig. 2).

In multivariate analyses considering age, FIGO stage, grading, and residual tumor after primary surgery, p53 mutational status remained a significant prognosticator for overall (hazard ratio, 1.888; 95\% confidence interval, 1.1-3.241; $\mathrm{p}=0.021$ ), but not for recurrence-free survival (hazard ratio, $1.672 ; 95 \%$ confidence interval, $0.961-2.91 ; \mathrm{p}=0.069$ ) in patients 
with the T-allele (T/T and T/G genotype). In the entire group of ovarian cancer patients the significance of p53 mutational status for prognosis was lost in multivariate analyses.

MDM2 SNP309 (T/T vs. T/G vs. G/G) and MDM2 protein expression (positive vs. negative) did not influence prognosis in the examined 198 patients with primary ovarian cancer.

\section{Discussion}

In the present study the MDM2 SNP309 itself was not of prognostic value, but modified the prognostic relevance of the p53 mutational status in patients with ovarian cancer. Only in patients with the $\mathrm{T} / \mathrm{G}$ and $\mathrm{T} / \mathrm{T}$ genotype, but not in $\mathrm{G} / \mathrm{G}$ carriers, did p53 wild-type carcinomas show a significantly improved prognosis as compared to p53 mutant carcinomas. We hypothesize that the homozygous variant MDM2 SNP309 genotype weakens wild-type p53 activity by increasing MDM2 levels. Few previous studies have performed combined analyses of the MDM2 SNP309 and p53. As in our study, p53 mutational status was seen to be associated with survival in breast cancer patients harboring the $\mathrm{T} / \mathrm{T}$, but not the $\mathrm{T} / \mathrm{G}$ and $\mathrm{G} / \mathrm{G}$ genotype (21).

The prevalence of the homozygous SNP309 variant genotype in our cohort is in line with previous studies in Caucasian patients with ovarian cancer that reported frequencies of $7.8-17.2 \%$ (22-24) and does not significantly differ from the $12 \%$ prevalence observed in healthy Caucasians (2). Also, the MDM2 SNP309 has not been linked with ovarian cancer susceptibility of Caucasian women in two case-control studies $(22,25)$. In contrast, the presence of at least one G-allele significantly decreased the risk for ovarian cancer in Chinese women (26). Interestingly, the prevalence of the G/G genotype significantly varies with respect to ethnicity and was $31 \%$ in healthy Chinese women.

In accordance with two previous studies of ovarian cancer $(22,23)$, the G-allele was not associated with younger age at diagnosis in the examined ovarian cancer cases. Bartel et al reported an 8.5-year earlier diagnosis in $\mathrm{G} / \mathrm{G}$ and $\mathrm{T} / \mathrm{G}$ as compared to T/T carriers in patients with FIGO III ovarian carcinomas with high estrogen receptor (ER) expression (24). Bond et al hypothesized that the G-allele of the MDM2 SNP309 may require an active estrogen-signaling pathway in the tumor to accelerate carcinogenesis (27). The estrogen binding site lies in the direct vicinity to the SNP309 on the MDM2 promoter. The G-allele of the SNP309 increases the affinity of the transcriptional factor Sp1, which also is a wellknown co-transcriptional activator of the ER. The present study, however, did not determine ER status.

The MDM2 SNP309 did not constitute a prognostic marker in the examined ovarian cancer cases. Previous studies of ovarian cancer have reported inconsistent results. Galic et al did not find a prognostic relevance of the MDM2 SNP309 in 150 patients with ovarian cancer (23). Bartel et al observed improved overall survival of patients with FIGO III carcinomas displaying a G-allele compared to the T/T genotype (24).

While the percentage of positive MDM2 staining was higher in $\mathrm{G} / \mathrm{G}$ as compared to $\mathrm{T} / \mathrm{G}$ and $\mathrm{T} / \mathrm{T}$ carriers, this difference did not reach statistical significance. Our finding is in accordance with a previous study of gynecologic carcinomas showing no significant correlation between MDM2 SNP309 and MDM2 protein levels (28). In a small study of renal cancer, however, MDM2 expression was detected significantly more often in G/G (5 of 10) than in T/T ( 2 of 15) carriers (19). MDM2 protein levels are not only related to the MDM2 SNP309 but also to various upstream signaling pathways. For instance, Ras and ERK as well as TGF $\beta$ have been shown to regulate MDM2 expression (2).

The rate of MDM2 protein expression lies well within the previously reported $9-42 \%$. Again, the prognostic value of MDM2 expression in ovarian cancer is controversial. Two studies found no prognostic relevance of MDM2 expression in ovarian cancer $(29,30)$, whereas Dogan et al reported a significantly impaired overall survival in MDM2 positive as compared to MDM2 negative ovarian carcinomas (31).

In conclusion, we hypothesize that the $\mathrm{G} / \mathrm{G}$ genotype of the MDM2 SNP309 may cause a functional impairment of the p53 pathway, thereby modifying the association between the p53 mutational status and prognosis in ovarian cancer.

\section{Acknowledgements}

This study was supported by 'Medizinischer Forschungsfond (MFF) Tirol'.

\section{References}

1. Manfredi JJ: The Mdm2-p53 relationship evolves: Mdm2 swings both ways as an oncogene and a tumor suppressor. Genes Dev 24: 1580-1589, 2010

2. Bond GL, Hu W, Bond EE, Robins H, Lutzker SG, Arva NC, Bargonetti J, Bartel F, Taubert H, Wuerl P, Onel K, Yip L, Hwang J, Strong LC, Lozano G and Levine AJ: A single nucleotide polymorphism in the MDM2 promoter attenuates the p53 tumor suppressor pathway and accelerates tumor formation in humans. Cell 119: 591-602, 2004.

3. Post SM, Quintás-Cardama A, Pant V, Iwakuma T, Hamir A, Jackson JG, Maccio DR, Bond GL, Johnson DG, Levine AJ and Lozano G: A high-frequency regulatory polymorphism in the p53 pathway accelerates tumor development. Cancer Cell 18: 220-230, 2010.

4. Wilkening S, Bermejo JL and Hemminki K: MDM2 SNP309 and cancer risk: a combined analysis. Carcinogenesis 28: 2262-2267, 2007.

5. Li Y, Zhao H, Sun L, Huang L, Yang Q and Kong B: MDM2 SNP309 is associated with endometrial cancer susceptibility: a meta-analysis. Hum Cell 24: 57-64, 2011.

6. Liu GY, Jiang DK, Shen SQ and Yu L: MDM2 SNP309T>G Polymorphism with Hepatocellular Carcinoma Risk: a metaanalysis. Arch Med Res 42: 149-155, 2011.

7. Huang SF, Chen IH, Liao CT, Wang HM, Liou SH and Hsieh LL: Combined effects of MDM2 SNP 309 and p53 mutation on oral squamous cell carcinomas associated with areca quid chewing. Oral Oncol 45: 16-22, 2009.

8. Nakashima M, Kondo S, Shimizu Y, Wakisaka N, Murono S, Furukawa M and Yoshizaki T: Impact of MDM2 single nucleotide polymorphism on tumor onset in head and neck squamous cell carcinoma. Acta Otolaryngol 128: 808-813, 2008.

9. Grochola LF, Müller TH, Bond GL, Taubert H, Udelnow A and Würl P: MDM2 SNP309 associates with accelerated pancreatic adenocarcinoma formation. Pancreas 39: 76-80, 2010.

10. Yoon YJ, Chang HY, Ahn SH, Kim JK, Park YK, Kang DR, Park JY, Myoung SM, Kim do Y, Chon CY and Han KH: MDM2 and p53 polymorphisms are associated with the development of hepatocellular carcinoma in patients with chronic hepatitis B virus infection. Carcinogenesis 29: 1192-1196, 2008.

11. Sanchez-Carbayo M, Socci ND, Kirchoff T, Erill N, Offit K, Bochner BH and Cordon-Cardo C: A polymorphism in HDM2 (SNP309) associates with early onset in superficial tumors, TP53 mutations, and poor outcome in invasive bladder cancer. Clin Cancer Res 13: 3215-3220, 2007.

12. Yarden RI, Friedman E, Metsuyanim S, Olender T, Ben-Asher E and Papa MZ: MDM2 SNP309 accelerates breast and ovarian carcinogenesis in BRCA1 and BRCA2 carriers of JewishAshkenazi descent. Breast Cancer Res Treat 111: 497-504, 2008. 
13. Nechushtan H, Hamburger T, Mendelson S, Kadouri L, Sharon N, Pikarsky E and Peretz T: Effects of the single nucleotide polymorphism at MDM2 309 on breast cancer patients with/without BRCA1/2 mutations. BMC Cancer 9: 60, 2009.

14. Copson ER, White HE, Blaydes JP, Robinson DO, Johnson PW and Eccles DM: Influence of the MDM2 single nucleotide polymorphism SNP309 on tumour development in BRCA1 mutation carriers. BMC Cancer 6: 80, 2006.

15. Chrisanthar R, Knappskog S, Løkkevik E, Anker G, Ostenstad B, Lundgren S, Risberg T, Mjaaland I, Skjønsberg G, Aas T, Schlichting E, Fjösne HE, Nysted A, Lillehaug JR and Lønning PE: Predictive and prognostic impact of TP53 mutations and MDM2 promoter genotype in primary breast cancer patients treated with epirubicin or paclitaxel. PLoS One 6: e19249, 2011.

16. Liu G, Wheatley-Price P, Zhou W, Park S, Heist RS, Asomaning K, Wain JC, Lynch TJ, Su L and Christiani DC: Genetic polymorphisms of MDM2, cumulative cigarette smoking and nonsmall cell lung cancer risk. Int J Cancer 122: 915-918, 2008.

17. Tu HF, Chen HW, Kao SY, Lin SC, Liu CJ and Chang KW: MDM2 SNP 309 and p53 codon 72 polymorphisms are associated with the outcome of oral carcinoma patients receiving postoperative irradiation. Radiother Oncol 87: 243-252, 2008.

18. Ohmiya N, Taguchi A, Mabuchi N, Itoh A, Hirooka Y, Niwa Y and Goto H: MDM2 promoter polymorphism is associated with both an increased susceptibility to gastric carcinoma and poor prognosis. J Clin Oncol 24: 4434-4440, 2006.

19. Hirata H, Hinoda Y, Kikuno N, Kawamoto K, Suehiro Y, Tanaka Y and Dahiya R: MDM2 SNP309 polymorphism as risk factor for susceptibility and poor prognosis in renal cell carcinoma. Clin Cancer Res 13: 4123-4129, 2007.

20. Concin N, Becker K, Slade N, Erster S, Mueller-Holzner E, Ulmer H, Daxenbichler G,Zeimet A,Zeillinger R, Marth C and Moll UM Transdominant DeltaTAp73 isoforms are frequently up-regulated in ovarian cancer. Evidence for their role as epigenetic p53 inhibitors in vivo. Cancer Res 64: 2449-2460, 2004.

21. Boersma BJ, Howe TM, Goodman JE, Yfantis HG, Lee DH, Chanock SJ and Ambs S: Association of breast cancer outcome with status of p53 and MDM2 SNP309. J Natl Cancer Inst 98 : 911-919, 2006.

22. Campbell IG, Eccles DM and Choong DY: No association of the MDM2 SNP309 polymorphism with risk of breast or ovarian cancer. Cancer Lett 240: 195-197, 2006.
23. Galic V, Willner J, Wollan M, Garg R, Garcia R, Goff BA, Gray HJ and Swisher EM: Common polymorphisms in TP53 and MDM2 and the relationship to TP53 mutations and clinical outcomes in women with ovarian and peritoneal carcinomas. Genes Chromosomes Cancer 46: 239-247, 2007.

24. Bartel F, Jung J, Böhnke A, Gradhand E, Zeng K, Thomssen C and Hauptmann S: Both germ line and somatic genetics of the p53 pathway affect ovarian cancer incidence and survival. Clin Cancer Res 14: 89-96, 2008.

25. Ueda M, Yamamoto M, Nunobiki O, Toji E, Sato N, Izuma S, Okamoto Y, Torii K and Noda S: Murine double-minute 2 homolog single nucleotide polymorphism 309 and the risk of gynecologic cancer. Hum Cell 22: 49-54, 2009.

26. Kang S, Wang DJ, Li WS, Wang N, Zhou RM, Sun DL, Duan YN, $\mathrm{Li} \mathrm{SZ}, \mathrm{Li} \mathrm{XF}$ and Li Y: Association of $\mathrm{p} 73$ and MDM2 polymorphisms with the risk of epithelial ovarian cancer in Chinese women. Int J Gynecol Cancer 19: 572-577, 2009.

27. Bond GL, Hirshfield KM, Kirchhoff T, Alexe G, Bond EE, Robins H, Bartel F, Taubert H, Wuerl P, Hait W, Toppmeyer D, Offit K and Levine AJ: MDM2 SNP309 accelerates tumor formation in a gender-specific and hormone-dependent manner. Cancer Res 66: 5104-5110, 2006.

28. Krekac D, Brozkova K, Knoflickova D, Hrstka R, Muller P, Nenutil R and Vojtesek B: MDM2SNP309 does not associate with elevated MDM2 protein expression or breast cancer risk. Oncology 74: 84-87, 2008.

29. Sengupta PS, McGown AT, Bajaj V, Blackhall F, Swindell R, Bromley M, Shanks JH, Ward T, Buckley CH, Reynolds K, Slade RJ and Jayson GC: p53 and related proteins in epithelial ovarian cancer. Eur J Cancer 36: 2317-2328, 2000.

30. Baekelandt M, Kristensen GB, Nesland JM, Tropé CG and Holm R: Clinical significance of apoptosis-related factors p53, $\mathrm{Mdm} 2$, and Bcl-2 in advanced ovarian cancer. J Clin Oncol 17: 2061, 1999.

31. Dogan E, Saygili U, Tuna B, Gol M, Gürel D, Acar B and Koyuncuoğlu M: p53 and mdm2 as prognostic indicators in patients with epithelial ovarian cancer: a multivariate analysis. Gynecol Oncol 97: 46-52, 2005. 